\title{
Morphological analysis of occipital condyles and foramen magnum as a guide for lateral surgical approaches
}

\begin{abstract}
Objectives: Surgical approaches to the craniovertebral junction (CVJ) are associated with a high mortality and morbidity when undertaken without detailed morphologic analysis of the region. In spite of the clinical importance of this area, there are only few anatomical reports are available in the literature. The aim of the present study was to present the detailed anatomy of the foramen magnum (FM) and occipital condyle (OC) for surgical approaches to the $\mathrm{CVJ}$ region.
\end{abstract}

Methods: Morphometric analysis was performed on 100 dried human occipital bones of unknown sex and age from Turkish population. Four parameters were measured for FM and eleven parameters for OC. FM shapes were classified. FM index was calculated.

Results: The antero posterior and transverse diameters of FM were $35,17 \pm 2,94 \mathrm{~mm}$ and $29,73 \pm 2,53 \mathrm{~mm}$, respectively. Anterior and posterior intercondylar distances were $22,47 \pm 2,98 \mathrm{~mm}$ and $41,54 \pm 3,78 \mathrm{~mm}$. Antero posterior and transverse diameters of OC were $23,47 \pm 2,44 \mathrm{~mm}$ and $11,40 \pm 1,41 \mathrm{~mm}$. Sagittal intercondylar angle was $31,72 \pm 3,48$ degrees on the right and $33,29 \pm 3,25$ degrees on the left side. OC anterior tip-opisthion distance was $39,62 \pm 3,19 \mathrm{~mm}$ on the right and $39,21 \pm 3,72 \mathrm{~mm}$ on the left side; there was a significant difference between the right and left side for these two parameters $(\mathrm{p}<0.05)$. FM was classified into seven morphological shapes; tetragonal shape was the most commonly observed (24\%).

Conclusion: This study gives a detailed morphological analysis of the CVJ, showing that most of the CVJ parameters are variable. Each surgical approach to this area has advantages, disadvantages, limitations and potential risks. Anatomical structures must be well-known and clinical and radiological diagnostic procedures like plain radiography, computed tomography and magnetic resonance imagining should be performed before surgery.

Keywords: craniovertebral junction, foramen magnum, morphometry, occipital condyle, surgical approach
Volume 3 Issue 6 - 2017

\author{
Pelin Ilhan,' Buse Kayhan,' Mete Erturk,' \\ Gulgun Sengul',2 \\ 'Department of Neuroscience, Ege University, Turkey \\ ${ }^{2}$ Department of Anatomy, Ege University, Turkey
}

Correspondence: Gulgun Sengul, Department of Anatomy, School of Medicine, Ege University, 35100, Bornova, Izmir,Turkey, Tel+905326860921, Email gulgun.sengul@gmail.com

Received: November 27, 2017 | Published: June 23, 2017
Abbreviations: CVJ, craniovertebral junction; FM, foramen magnum; OC, occipital condyle

\section{Introduction}

Craniovertebral junction (CVJ) refers to an area that includes the foramen magnum (FM), occipital condyles (OCs) and the first two cervical vertebrae, namely atlas and axis. ${ }^{1} \mathrm{FM}$ is in the center of the skull base and has three parts: the dorsal part of the FM (the squamosal part), the ventral part of FM (the basal or clival part), and the condylar part connecting the squamosal and the clival parts. The condylar part includes the OC, posterior margin of the jugular foramen and the hypoglossal canal. ${ }^{2} \mathrm{OC}$ is the only articulation between the occipital and the atlas. ${ }^{3}$

CVJ is associated with many important structures such as the medulla oblongata, upper spinal and low cranial nerves (glossopharyngeus, vagus, accessorius and hypoglossus), vertebral arteries with its branches and vertebral veins, as well as the atlas, axis and occipital bone with important ligamentous and muscular attachments. $^{4}$
Embryology and developmental anatomy of this region is important for understanding pathologies on this region. ${ }^{5}$ The measurements of structures vary in different stages of human life $^{6}$ and with diseases such as Down syndrome. ${ }^{7}$ According to Nevel \& Wood, ${ }^{8}$ the base of cranium that includes the basioccipital, sphenoid and temporal bones continued to evolve and had significant morphological changes within hominid clade. There are also many developmental and ethnic variations in humans. ${ }^{6}$ Therefore, this area has variable shapes, sizes and angles.

The most frequently reported lesions are extra and intradural tumors, vertebral artery lesions, rheumatoid diseases and malformations of the CVJ, synovial cysts, infections, syringobulbia and intrinsic lesions. ${ }^{9}$ Occipitocervical synostosis is one of the most frequent osseous anomalies of the CVJ and may compress the brainstem, vertebral artery and cranial nerves. ${ }^{10}$

Many surgical approaches are associated with high mortality and morbidity when undertaken without detailed morphological analysis. ${ }^{11}$ The shape, size and angle of the OC is important when choosing the surgical approach. ${ }^{12}$ The kinetic anatomy of CVJ, bony configuration, 
vascular supply and course of the sub occipital vertebral arteries are important for skull base surgery. ${ }^{1}$ In spite of the clinical importance of this area, there are only few anatomical reports available in the literature. The aim of the present study was to determine and define the detailed anatomy of the FM and OC for surgical approaches of the region.

\section{Materials and methods}

Morphometric analysis was performed on one hundred dried human occipital bones from a Turkish population of unknown sex and age, obtained from the bone collection of Ege University, School of Medicine, Izmir, Turkey. Measurements were made using a digital caliper accurate to $0,01 \mathrm{~mm}$ and a protractor.

Four parameters were measured for FM and eleven parameters for OC based on the detailed study of Naderi et al. ${ }^{3}$ The parameters were anterior and posterior intercondylar distances (Figure 1A \& Figure 1C), transverse distance between two OCs (Figure 1B), sagittal intercondylar angle (Figure 2), anteroposterior length of OC (Figure 3A), transverse diameter of the OC (Figure 3B), the height of the OC (Figure 4), the distance between anterior tip of the OC and opisthion (Figure 5B), the distance between anterior tip of the $\mathrm{OC}$ and basion (Figure 5C), the distance between posterior tip of the $\mathrm{OC}$ and opisthion (Figure 5B), and the distance between posterior tip of the $\mathrm{OC}$ and basion (Figure 5D). For FM, anteroposterior length and transverse diameter was measured (Figure 3C \& Figure 3D), FM index was calculated and FM shapes were observed.

FM shape was classified into seven types according to Chethan et al., ${ }^{13}$ round, egg-shaped, tetragonal, oval, irregular, hexagonal and pentagonal (Figure 6). FM index was calculated by dividing the anteroposterior diameter of FM by transverse diameter. Some measurements were made separately for the right and left sides. Right-left differences were assessed using paired t-test (Table 1). Data were presented as means \pm SEM (standard error of mean). P value less than $0.05(\mathrm{p} \leq 0.05)$ was considered statistically significant.

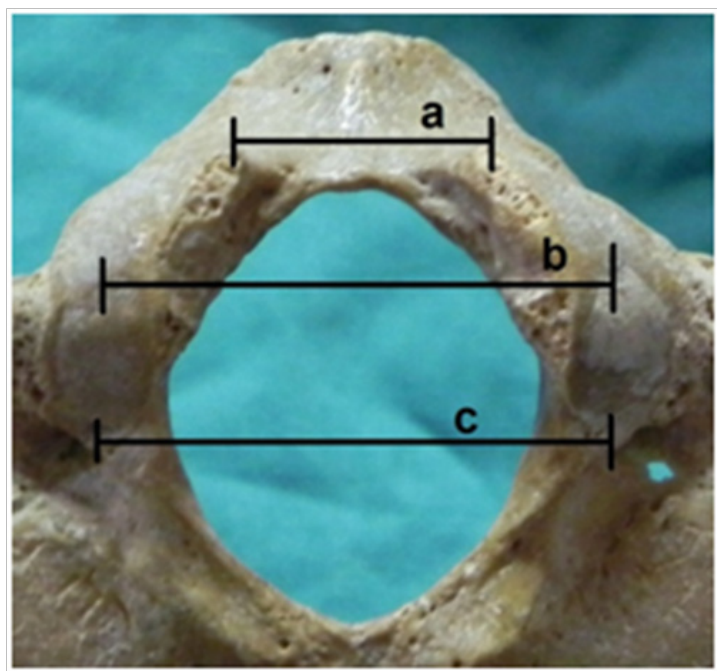

Figure I Intercondylar distances of the occipital bone.

A. Anterior intercondylar distance (the distance between two anterior tips of OCs);

B. Distance between two tops of OCs;

C. Posterior intercondylar distance (the distance between two posterior tips of OCs).

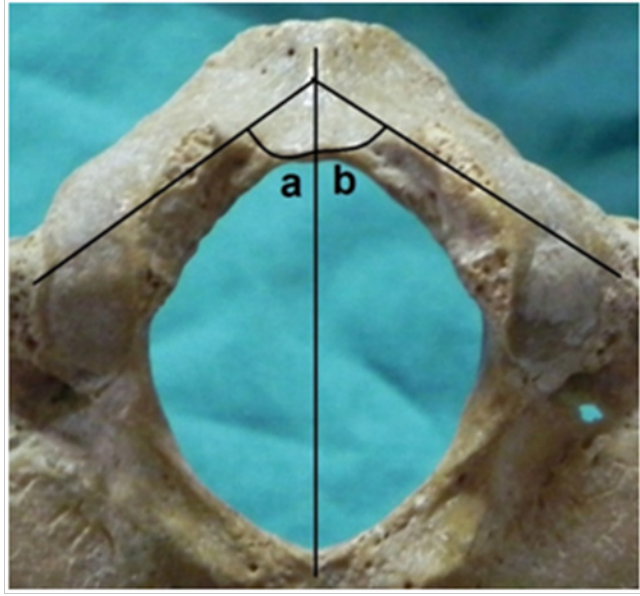

Figure 2 The condylar angles.

A. Right sagittal condylar angle;

B. Left sagittal condylar angle;

C. Sagittal intercondylar angle $(a+b)$.

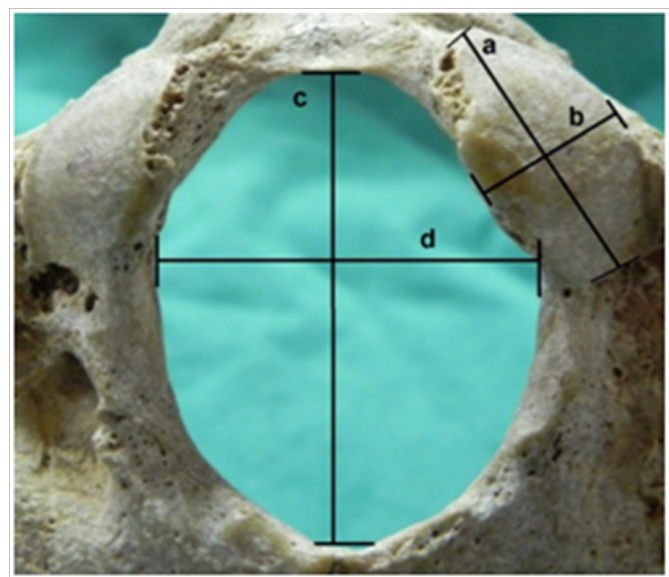

Figure 3 The condylar angles.

A. Right sagittal condylar angle;

B. Left sagittal condylar angle;

Sagittal intercondylar angle $(a+b)$.

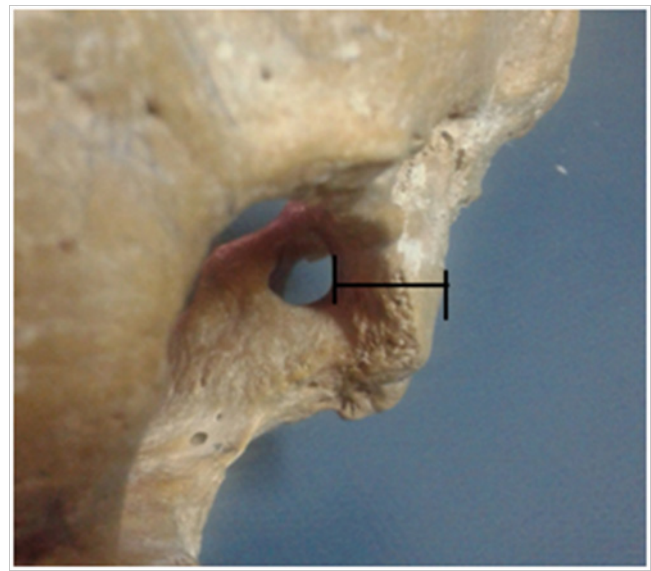

Figure 4 Height of the $\mathrm{OC}$ measured as the distance between the intracranial hypoglossal canal and midline of the OC. 


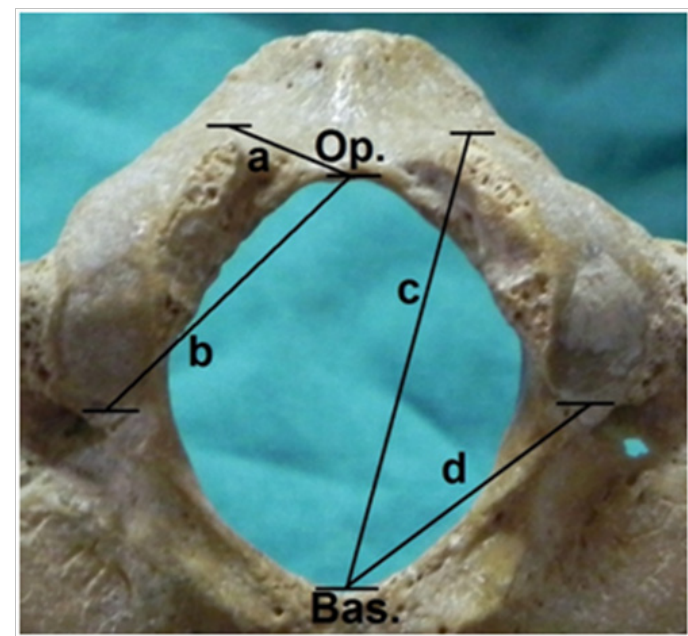

Figure 5 Distances between $\mathrm{OC}$ and opisthion, $\mathrm{OC}$ and basion.
A. Distance between anterior tip of $\mathrm{OC}$ and opisthion;
B. Distance between posterior tip of $\mathrm{OC}$ and opisthion;
C. Distance between anterior tip of $\mathrm{OC}$ and basion;
D. Distance between posterior tip of OC and basion.
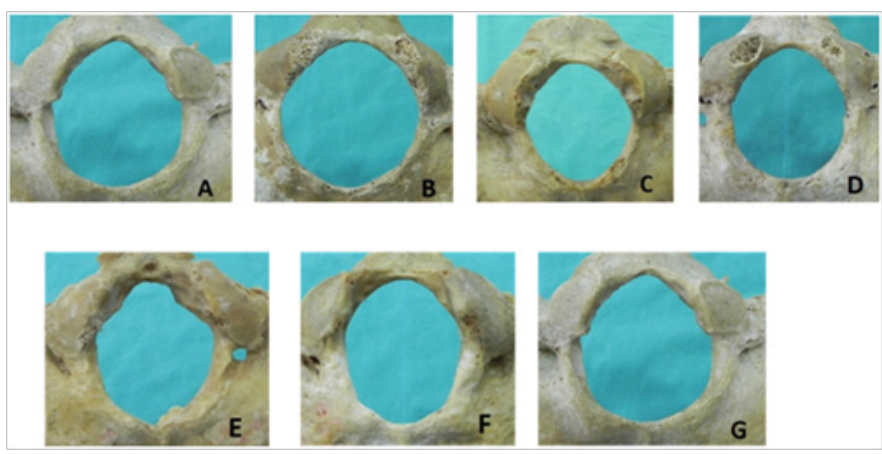

Figure 6 FM shapes.
A. Egg;
B. Round;
C. Tetragonal;
D. Oval;
E. Irregular;
F. Hexagonal;
G. Pentagonal.

Table I Measurements for the OC and FM (mean \pm SD). *, $p<0.05$

\begin{tabular}{|c|c|c|c|c|c|}
\hline Parameter & $\mathbf{N}$ & Mean $\pm S D(m m)$ & $\operatorname{Min}(\mathbf{m m})$ & $\operatorname{Max}(\mathrm{mm})$ & $\mathbf{p}$ \\
\hline Anterior intercondylar distance & 96 & $22,47 \pm 2,98$ & 15,86 & 29,45 & \\
\hline Posterior intercondylar distance & 98 & $41,54 \pm 3,78$ & 32,9 & 52,31 & \\
\hline Transverse distance between two OC & 98 & $37,21 \pm 3,19$ & 29,08 & 45,06 & \\
\hline Anteroposterior diameter of FM & 100 & $35,18 \pm 2,94$ & 28,01 & 43,44 & \\
\hline Transverse diameter of FM & 99 & $29,73 \pm 2,54$ & 20,86 & 35,65 & \\
\hline Sagittal condylar angle (R) & 98 & $31,72 \pm 3,48^{\circ}$ & $25^{\circ}$ & $46^{\circ}$ & \\
\hline Sagittal condylar angle (L) & 98 & $33,29 \pm 3,25^{\circ}$ & $27^{\circ}$ & $49^{\circ}$ & \\
\hline Sagittal intercondylar angle & 98 & $64,83 \pm 4,73^{\circ}$ & $55^{\circ}$ & $84^{\circ}$ & $0^{*}$ \\
\hline Length of $O C(R)$ & 97 & $23,44 \pm 2,60$ & 16,45 & 31,06 & \\
\hline Length of $\mathrm{OC}(\mathrm{L})$ & 97 & $23,49 \pm 2,71$ & 16,65 & 30,15 & \\
\hline Length of OC (total) & 98 & $23,47 \pm 2,44$ & 17,17 & 30,6 & 0,751 \\
\hline Width of OC (R) & 98 & $|I, 3| \pm 1,78$ & 8,23 & 19,34 & \\
\hline Width of OC (L) & 98 & 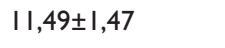 & 8,36 & 14,52 & \\
\hline Width of OC (total) & 98 & $\mid \mathrm{I}, 4 \pm \mathrm{I}, 4 \mathrm{I}$ & 8,59 & 15,99 & 0,273 \\
\hline Height of OC (R) & 98 & $9,04 \pm 1,18$ & 6,01 & 12,02 & \\
\hline Height of OC (L) & 98 & $9,02 \pm 1,22$ & 5,71 & II,64 & \\
\hline Height of $O C$ (total) & 98 & $9,03 \pm 1,13$ & 6,13 & 11,45 & 0,871 \\
\hline OCAT-Op (R) & 97 & $39,62 \pm 3,19$ & 32,09 & 48,22 & \\
\hline OCAT-Op (L) & 97 & $39,21 \pm 3,72$ & 25,21 & 48,67 & \\
\hline OCAT-Op (total) & 98 & $39,43 \pm 3,34$ & 29,6 & 47,4 & $0,019 *$ \\
\hline OCAT-Bas (R) & 97 & $11,99 \pm 2,2$ & 1,68 & $|7,8|$ & \\
\hline OCAT-Bas (L) & 97 & $12,2 \pm 1,86$ & 8,04 & 15,96 & \\
\hline OCAT-Bas (total) & 98 & $12,09 \pm 1,76$ & 6,43 & 16,67 & 0,364 \\
\hline OCPT-Op (R) & 98 & $27,54 \pm 3,13$ & 19,67 & 39,68 & \\
\hline
\end{tabular}




\begin{tabular}{|c|c|c|c|c|c|}
\hline Parameter & $\mathbf{N}$ & Mean $\pm S D(m m)$ & $\operatorname{Min}(\mathrm{mm})$ & $\operatorname{Max}(\mathrm{mm})$ & $\mathbf{p}$ \\
\hline ОСРТ-Op (L) & 98 & $27,5 \pm 2,56$ & 21,57 & 36,41 & \\
\hline ОСРТ-Op (total) & 98 & $27,52 \pm 2,59$ & 21,15 & 35,26 & 0,863 \\
\hline OCPT-Bas (R) & 98 & $27,91 \pm 3,48$ & 21,44 & 47,64 & \\
\hline OCPT-Bas (L) & 98 & $27,96 \pm 2,48$ & 22,6 & 35,67 & \\
\hline OCPT-Bas (total) & 98 & $27,93 \pm 2,67$ & 22,06 & 39,49 & 0,869 \\
\hline FM index & 99 & $1,19 \pm 0,09$ & 0,95 & $\mathrm{I}, 44$ & \\
\hline
\end{tabular}

FM, foramen magnum; R, right; L, left; OC, occipital condyle; OCAT, oc anterior tip; Op, opisthion; OCPT, oc posterior tip; Bas, basion

Table 2 Anteroposterior and transverse diameters of the FM ( $\mathrm{mm})$ and FM index

\begin{tabular}{|c|c|c|c|c|c|c|c|c|}
\hline Parameters & $\begin{array}{l}\text { Wanebo \& } \\
\text { Chicoine } \\
\text { n=32 } \\
\text { Caucasian }\end{array}$ & $\begin{array}{l}\text { Murshed et } \\
\text { al. }{ }^{33} n=110 \\
\text { Turkish }\end{array}$ & $\begin{array}{l}\text { Muthukumar } \\
\text { et al. }{ }^{37} n=50 \\
\text { Indian }\end{array}$ & $\begin{array}{l}\text { Naderi et } \\
\text { al. }{ }^{3} \mathrm{n}=202 \\
\text { Turkish }\end{array}$ & $\begin{array}{l}\text { Kizilkanat } \\
\text { et al. }{ }^{34} n=59 \text {, } \\
\text { Turkish }\end{array}$ & $\begin{array}{l}\text { Tubbs et } \\
\text { al. }{ }^{36} \mathrm{n}=72 \\
\text { Caucasian }\end{array}$ & $\begin{array}{l}\text { Chethan et } \\
\text { al. }{ }^{13} n=53 \\
\text { Indian }\end{array}$ & $\begin{array}{l}\text { Present study } \\
n=100 \text { Turkish }\end{array}$ \\
\hline Antero-posterior & 36 & $35,9 \pm 2$ & 33,3 & 34,7 & 34,8 & 31 & $31 \pm 1,8$ & $35,18 \pm 2,94$ \\
\hline Transverse & 28,3 & $30,4 \pm 2$ & 27,9 & & 29,6 & 27 & $25,2 \pm 2,4$ & $29,73 \pm 2,54$ \\
\hline
\end{tabular}

Table 3 Comparison of FM shapes with earlier studies

\begin{tabular}{|c|c|c|c|c|c|}
\hline FM shape & $\begin{array}{l}\text { Chethan et al., } \\
n=53 \text { Indian }\end{array}$ & $\begin{array}{l}\text { Zaidi \& Dayal }{ }^{14} \\
\text { n=200 Indian }\end{array}$ & $\begin{array}{l}\text { Sindel et al., } \\
\text { n=95 Turkish }\end{array}$ & $\begin{array}{l}\text { Murshed et al., }{ }^{33} \\
\text { n= I I } 0 \text { Turkish }\end{array}$ & $\begin{array}{l}\text { Present study } \\
(n=100) \text { Turkish }\end{array}$ \\
\hline Round & $22,6 \%$ & $0,5 \%$ & $15,8 \%$ & $21,8 \%$ & $6 \%$ \\
\hline Egg & $18,9 \%$ & - & - & $6,3 \%$ & $12 \%$ \\
\hline Tetragonal & $18,9 \%$ & - & $49,4 \%$ & $12,7 \%$ & $24 \%$ \\
\hline Oval & $15,1 \%$ & $64 \%$ & $18,9 \%$ & $8,1 \%$ & $10 \%$ \\
\hline Irregular & $15,1 \%$ & $3,5 \%$ & $6,3 \%$ & $10,9 \%$ & $22 \%$ \\
\hline Hexagonal & $5,6 \%$ & $24,5 \%$ & $5,3 \%$ & $17,2 \%$ & $21 \%$ \\
\hline Pentagonal & $3,8 \%$ & $7,5 \%$ & $4,2 \%$ & $13,6 \%$ & $2 \%$ \\
\hline
\end{tabular}

Table 4 Comparison of OC parameters with earlier studies

\begin{tabular}{|c|c|c|c|c|c|c|c|}
\hline Parameters & $\begin{array}{l}\text { Naderi et al. }{ }^{3} \\
n=202 \text { Turkish }\end{array}$ & $\begin{array}{l}\text { Kalthur et } \\
\text { al. }{ }^{9} n=7 \text { I } \\
\text { Indian }\end{array}$ & $\begin{array}{l}\text { Kizilkanat } \\
\text { et al. }{ }^{34} n=59 \\
\text { Turkish }\end{array}$ & $\begin{array}{l}\text { Bozbuga et } \\
\text { al. }{ }^{41} \mathrm{n}=78 \\
\text { Turkish }\end{array}$ & $\begin{array}{l}\text { Olivier }^{42} \\
n=125, \text { French }\end{array}$ & $\begin{array}{l}\text { Muthukumar } \\
\text { et al. }{ }^{37} n=50 \\
\text { Indian }\end{array}$ & $\begin{array}{l}\text { Present study } \\
n=100, \text { Turkish } \\
2015\end{array}$ \\
\hline Length of OC & 23,6 & $22 \pm 2$ & 24,5 & - & 23,7 & 26,6 & $23,47 \pm 2,44$ \\
\hline Width of OC & 10,5 & $11 \pm 2$ & $|3|$, & - & II,5 & 14,7 & $|\mathrm{I}, 4 \pm|, 4 \mathrm{I}$ \\
\hline Height of OC & 9,2 & - & - & - & 8,8 & - & $9,03 \pm 1,13$ \\
\hline ОСРТ-Op & $26,4 \pm 2,3$ & $28 \pm 2$ & - & - & - & - & $27,52 \pm 2,59$ \\
\hline OCPT-Bas & $27,8 \pm 2,9$ & $27 \pm 2$ & - & - & - & - & $27,93 \pm 2,67$ \\
\hline OCAT-Op & $39,0 \pm 2,9$ & $39 \pm 3$ & - & - & - & - & $39,43 \pm 3,34$ \\
\hline OCAT- Bas & $10,8 \pm 1,5$ & $12 \pm 2$ & - & - & - & - & $12,09 \pm 1,76$ \\
\hline $\begin{array}{l}\text { Anterior intercondylar } \\
\text { distance }\end{array}$ & $21 \pm 2,8$ & - & 22,6 & 22,8 & - & - & $22,47 \pm 2,98$ \\
\hline $\begin{array}{l}\text { Posterior intercondylar } \\
\text { distance }\end{array}$ & $4 I, 6 \pm 2,9$ & - & 44,2 & 30,2 & - & - & $4 I, 54 \pm 3,78$ \\
\hline
\end{tabular}

OC, occipital condyle; OCPT-Op, the distance between OC posterior tip and opisthion; OCPT-Bas, the distance between OC posterior tip and basion; OCATOp, the distance between OC anterior tip and opisthion; OCAT-Bas, the distance between OC anterior tip and basion 


\section{Results}

The measurements of $\mathrm{OC}$ and FM for a total of 14 parameters are shown in Table 1. There were statistically significant differences between the right and left sides for the occipital condyleanterior tipopisthion distance (OCAT-Op) and sagittal condylar angle $(\mathrm{p}<0,05)$, but no significant differences were found between right and left sides for the remaining parameters.

We measured the anteroposterior diameter of FM as $35,18 \pm 2,94 \mathrm{~mm}$, transverse diameter as $29,73 \pm 2,54 \mathrm{~mm}$, and $\mathrm{FM}$ index as $1,19 \pm 0,09$ (Table 2). The shape of FM was round in $6 \%$, egg-shaped in $12 \%$, tetragonal in $24 \%$, oval in $10 \%$, irregular in $22 \%$, hexagonal in $21 \%$ and pentagonal in $2 \%$ of the specimens (Table 3 ). The length, width and height of the OC were $23,47 \pm 2,44,11,4 \pm 1,41$ and $9,03 \pm 1,13$, consequently. The OCPT-Op distance was measured as $27,52 \pm 2,59 \mathrm{~mm}$, OCPT-Bas as $27,93 \pm 2,67 \mathrm{~mm}$, OCAT-Op as $39,43 \pm 3,34 \mathrm{~mm}$, and OCAT- Bas as $12,09 \pm 1,76 \mathrm{~mm}$. The anterior intercondylar distance was $22,47 \pm 2,98 \mathrm{~mm}$, and posterior inter condylar distancemm.41,54 $\pm 3,78$ (Table 4).

\section{Discussion}

CVJ is in close relationship with many important structures, and therefore, lesions involving this area have potential risks., ${ }^{4}$ Before surgery, clinical and radiological diagnostic procedures should be done and anatomical structures must be well identified. ${ }^{13}$

There are many factors that influence the treatment of CVJ lesions, such as etiology, location of the lesion, and the development of the individual. ${ }^{15}$ As CVJ lesions may cause different destructions on bones and neurovascular structures such as the vestibule basilar system and lower cranial nerves, different surgical approaches are used. ${ }^{15,16}$ Therefore, it is important to know the area and understand the limitations and potential risks for each approach. ${ }^{17}$ In the last four decades, numerous surgical approaches and endoscopic-assisted microsurgical techniques have been developed for CVJ pathologies. ${ }^{18}$ These surgical approaches may be classified as anterior, posterior and lateral approaches, each with advantages and disadvantages.

\section{Anterior approach}

Anterior approaches can be divided into trans oral, transmaxillar, transfrontal-transbasal, expanded frontal, transsphenoidal and transcervical. These approaches are used for reaching the lesions in atlas, axis and clivus or for fixation when there is a trauma in bone or ligaments which surround the odontoid process. The advantage is that lesions can be approached directly; the disadvantage is after removal of CSF fistulas, pseudomeningoceles and intradural lesions, there may be formed meningitis. ${ }^{19}$ Anterolateral approach is used for extradural and osseous tumors, ${ }^{20}$ especially vertebral artery pathologies. ${ }^{21}$

\section{Lateral approach}

CVJ lesions are currently approached by lateral approach. ${ }^{3}$ This approach is used also to remove the petrous part of temporal bone in different degrees for reaching the clival region. Lateral approaches include translabirynthine, transcochlear and anterior transpetrousal approaches, ${ }^{22}$ extreme lateral, far lateral, ${ }^{23}$ transfacetal, partial transcondylar, complete transcondylar, extreme-lateral transjugular and transtubercular approaches with or without division of the sigmoid sinus. ${ }^{3}$ Extreme lateral approach provides access to lesions in the middle of the FM. ${ }^{24,25,15}$

\section{Posterior approach}

Posterior approach is used for intradural tumors which are located at posterior or lateral part of the cervicomedullary junction. ${ }^{26}$ It has several advantages-there is no need for drilling the OCs or lateral mass, and postoperative recovery is fast. ${ }^{27}$ This approach can be divided into posterior suboccipital, posterolateral (lateral suboccipital), far lateral, ${ }^{23}$ standard para median suboccipital and transcondylar approaches. ${ }^{28,29}$

\section{Far lateral approach}

Far lateral approach is used for tumors in the anterior side of the cervicomedullary junction. ${ }^{28,29}$ Far lateral trans atlas approach is used for CVJ anomalies and rheumatoid arthritis. ${ }^{30}$ Far lateral approaches may be far lateral transcondylar, transcondylar, retrocondylar, supracondylar, transtubercular and condylar fossa approaches.,31 Far lateral approach provides good exposure and a lateral viewing trajectory for accessing intradural and extradural lesions located at the ventral FM, ventral and ventrolateral brainstem and CVJ without brain retraction. ${ }^{3,32}$ This approach is used for several types of tumors in this region, including FM meningiomas, schwannomas, chordomas, and chondrosarcomas. Vascular lesions, such as vertebral arteryposteroinferior cerebellar artery junction aneurysms, vertebrobasilar junction aneurysms, and ventrolaterally located brainstem cavernous malformations, can also be accessed with this approach. ${ }^{3}$ Extensive dissection of paravertebral muscles and vessels such as the vertebral artery and removal of bony structures such as the $\mathrm{OC}$ and jugular tubercle is required. These maneuvers may result in injury to vascular structures (vertebral artery, jugular vein and bulb) and lower cranial nerves, and may also lead to craniocervical instability due to removal of the OC. ${ }^{31}$

If the antero-posterior diameter of FM is wide, it provides a better surgical exposure making it very suitable for condylar resection. ${ }^{11}$ In transcondylar approach, the diameters of FM should be well known for a safe OC resection..$^{13}$ In our study, the anteroposterior diameter of FM was $35,18 \pm 2,94 \mathrm{~mm}$. This is similar to the findings of Murshed et al. ${ }^{33}$ as $35,9 \pm 2 \mathrm{~mm}$, Kizilkanat et al., ${ }^{34}$ as $34,8 \mathrm{~mm}$, Naderiet al., ${ }^{3}$ as $34,7 \pm 2,3 \mathrm{~mm}$, and Barut et al.35 as $35,6 \pm 2,45 \mathrm{~mm}$. Our measurement is larger than those of Chethan et al., ${ }^{13}$ as $31 \pm 1,8 \mathrm{~mm}$ and Tubbs \& Griessenauer $^{36}$ as $31 \mathrm{~mm}$ (Table 2).

FM index is also important for choosing the surgical approach. ${ }^{34}$ In patients with small FM, the transcondylar approach is more suitable. The gap between the FM and brainstem should be small in this approach. ${ }^{11}$ When FM index is $\geq 1.2$, the foramen is accepted to be ovoid. ${ }^{30}$ Our FM index is similar to those of Kizilkanat et al. ${ }^{34}$ and Chethanet al. ${ }^{13}$ (Table 2).

Variations in FM shape should be taken into consideration during clinical and radiological diagnostic procedures and surgical approaches to the region. This is also important for determining how much bone must be removed. ${ }^{34}$ In early fetal growth, during the development of skull base, FM is one of the centers of ossification ${ }^{37,38}$ and because of evolutionary changes in FM, shapes are variable. ${ }^{8}$ The irregular shape of FM may cause developmental anomalies of the bone and soft tissues at the CVJ. ${ }^{13}$ In our study, the most common FM shape was tetragonal (24\%). Chethan et al..$^{13}$ and Murshed et al..$^{33}$ found FM round, Zaidi \& Dayal ${ }^{14}$ oval \& Sindel et al ${ }^{39}$ hexagonal in shape (Table 3). The variations in the shape of the FM may be due to the ethnical group or population studied.

OCs are located anterolaterally to the FM. The shape, size, and angle of the $\mathrm{OC}$ is important for choosing the surgical procedure, and studies present varying findings for the measurements. ${ }^{12}$ Although a $1 / 3-2 / 3$ resection may not cause craniocervical instability, total resection may do so. ${ }^{35}$ The same amount of partial condylectomy may cause greater occipitocervical instability in a short OC compared to 
a long OC. Also, a long OC may require a more extensive resection for optimum visualization. Similar surgical considerations may be correct for the OC width. ${ }^{31}$ Surgery in a wider condyle may be more demanding. ${ }^{12}$

The comparison of our measurements for the length, width and height of the $\mathrm{OC}$, the anterior and posterior intercondylar distances are shown in Table 2. The distance between two OCs can lead to different anterior and posterior angles. Sagittal intercondylar angle ranges between $55^{\circ}$ and $84^{\circ}$. Our findings correlate with those of Barut et al., ${ }^{35} 63,7 \pm 7,75^{\circ}$ and Kizilkanat et al., ${ }^{34}$ as $62,2 \pm 9,1^{\circ}$. A wide range reflects the asymmetry in the orientation, length and shape of OCs and may affect the lateral approach. ${ }^{3}$ According to Açikbaş et al. ${ }^{40}$ condylectomy provides wider angle of exposure. Wide angle is an advantage for reaching to the ventral of the FM. ${ }^{12}$

The distance between the posterior tip of the $\mathrm{OC}$ and the opisthion is also important for surgical approaches. A larger distance provides a free corridor for posterolateral approaches ${ }^{3}$ and a longer corridor provides a wider space for a far lateral transcondylar approach. ${ }^{31}$ In our study, the distance between OC posterior tip and opisthion was $27,52 \pm 2,59 \mathrm{~mm}$, the distance between $\mathrm{OC}$ anterior tip and opisthion $39,43 \pm 3,34 \mathrm{~mm}$, and the distance between OC anterior tip and basion $12,09 \pm 1,76 \mathrm{~mm}$. Comparison of our findings with earlier studies is shown in Table 4. The measurements in these studies are similar in value, except for the posterior intercondylar distance measured by Bozbuga et al. ${ }^{41}$ which is lower, possibly due to different reference points taken for the measurement.

Regression analysis studies have been performed for the morphology of FM and $\mathrm{OC}$ in identification of sex, ethnic group and age. ${ }^{42}$ Although some studies suggested these did not have a correlation with the sagittal and the transverse diameter of the FM, ${ }^{43}$ other studies reported a sexual dimorphism for FM dimensions with all parameters being significantly higher in males. ${ }^{44}$ Kamath et al. ${ }^{45}$ found sex predictability (higher values in males) for FM area (70.3\%), followed by sagittal diameter $(69.6 \%)$, and least for transverse diameter (66.4\%), similar to the study of Uthman et al., ${ }^{46}$ for FM area and Raghavendra Babu et al. ${ }^{47}$ with higher predictability for FM area and sagittal diameter compared to transverse diameter. ${ }^{9}$ Rai et al. ${ }^{48}$ found $\mathrm{OC}$ and FM dimensions higher in males compared to females No stastistically significant difference was found in adults for different age groups for the $\mathrm{OC}^{49}$ and $\mathrm{FM} .{ }^{50}$ Varsha et al..$^{51}$ found that the anteroposterior diameter of the $\mathrm{OC}$ in male skulls was found higher than the female skulls, however there was no significant difference in the transverse diameter of $\mathrm{OC}$ in male and female skulls.

In summary, several anatomical parameters were measured for the FM and OC in this study to give a detailed morphometric analysis of the CVJ on a high number of occipital bones. The limitation of this study is the lack of knowledge regarding the age and gender of occipital bones studied.

\section{Conclusion}

CVJ is a complex area and most of the parameters here are variable. Therefore, before surgery, anatomical structures must be well known and clinical and radiological diagnostic procedures like plain radiography, computed tomography (CT) and magnetic resonance imagining (MRI) should be performed. It should be known that each surgical approach has advantages, disadvantages, limitations and potential risks. The findings of this study will provide a database for choosing the right surgical approach and also for successful instrumentation and minimizing mortality and morbidity in the region.

\section{Acknowledgements}

None.

\section{Conflict of interest}

Author declares that there is no conflict of interest.

\section{References}

1. Ha W, Yang D, Gu S, et al. Anatomical study of sub occipital vertebral arteries and surrounding bony structures using virtual reality technology. Med Sci Monit. 2014;20:802-806.

2. Menezes AH, Traynelis VC. Anatomy and biomechanics of normal craniovertebral junction (a) and biomechanics of stabilization (b). Childs Nerv Syst. 2008;24(10):1091-1100.

3. Naderi S, Korman E, Citak G, et al. Morphometric analysis of human occipital condyle. Clin Neurol Neurosurg. 2005;107(3):191-199.

4. Rhoton AL, de Olivera JE, Peace D. Microsurgical anatomy of the region of the foramen magnum. Surg Neurolog. 1985;24(3):293-352.

5. Hita Contreras F, Roda O, Martínez Amat A, et al. Embryonic and early fetal period development and morphogenesis of human craniovertebral junction. Clin Anat. 2014;27(3):337-345.

6. Burdan F, Szumiło J, Walocha J, et al. Morphology of the foramen magnum in young Eastern European adults. Folia Morphol (Warsz). 2012;71(4):205-216.

7. Pueschel SM, Scola FH, Tupper TB, et al. Skeletal anomalies of the upper cervical spine in children with Down syndrome. J Pediatr Orthop. 1990;10(5):607-611.

8. Nevell L, Wood B. Cranial base evolution within the hominin clade. $J$ Anat. 2008;212(4):455-468.

9. Kalthur SG, Padmashali S, Gupta C, et al. Anatomic study of the occipital condyle and its surgical implications in transcondylar approach. J Craniovertebr Junction Spine. 2014;5(2):71-77.

10. Mudaliar RP, Shetty S, Nanjundaiah K, et al. An osteological study of occipito cervical synostosis:its embryological and clinical significance. J Clin Diagn Res. 2013;7(9):1835-1837.

11. Wanebo JE, Chicoine MR. Quantitative analysis of the transcondylar approach to the foramen magnum. Neurosurgery. 2001;49(4):934-943.

12. Ozer MA, Celik S, Govsa F, et al. Anatomical determination of a safe entry point for occipital condyle screw using three dimensional landmarks. Eur Spine J. 2011;20(9):1510-1517.

13. Chethan P, Prakash KG, Murlimanju BV, et al. Morphological analysis and morphometry of the foramen magnum:an anatomical investigation. Turk Neurosurg. 2012;22(4):416-419.

14. Zaidi SH, Dayal SS. Variations in the shape of foramen magnum in Indian skulls. Anat Anz. 1988;167(4):338-340.

15. Jung SH, Jung S, Moon KS, et al. Tailored surgical approaches for benign craniovertebral junction tumors. J Korean Neurosurg Soc. 2010;48(2):139-144.

16. Lang DA, Neil Dwyer G, Iannotti F. The suboccipital transcondylar approach to the clivus and cranio-cervical junction for ventrally placed pathology at and above the foramen magnum. Acta Neurochir (Wien). $1993 ; 125(1-4): 132-137$.

17. Nakase H, Ohnishi H, Matsuyama T, et al. Two stage skull base surgery for tumours extending to the sub- and epidural spaces. Acta Neurochir (Wien). 1998;140(9):891-898.

18. Kshettry VR, Benzel EC. Endoscopic-assisted techniques at the craniovertebral junction:understanding indications and limitations. World Neuro surg. 2014;82(6):e711-e712. 
19. Rhoton, Albert L. The Foramen Magnum. In: Rhoton, Albert L, editors. The Posterior Cranial Fossa: Microsurgical Anatomy \& Surgical Approaches. Neurosurg. 2000;47(3):S155-S193.

20. George B, Lot G. Anterolateral and posterolateral approaches to the foramen magnum:technical description and experience from 97 cases. Skull Base Surg. 1995;5(1):9-19.

21. George B, Dematons C, Cophignon J. Lateral approach to the anterior portion of the foramen magnum. Application to surgical removal of 14 benign tumors: technical note. Surg Neurol. 1988;29(6):484-490.

22. Baldwin HZ, Miller CG, van Loveren HR, et al. The far lateral/combined supra- and infratentorial approach:A human cadaveric prosection model for routes of access to the petroclival region and ventral brain stem. $J$ Neuro surg. 1994;81(1):60-68.

23. Kshettry VR, Chotai S, Houa J, et al. Successful resection of anterio and anterolateral lesions at the craniovertebral junction using a simple posterolateral approach. J Clin Neurosci. 2014;21(4):616-622.

24. Bertalanffy H, Seeger W. The dorsolateral, suboccipital, transcondylar approach to the lower clivus and anterior portion of the craniovertebral junction. Neurosurg. 1991;29(6):815-821.

25. Sen CN, Sekhar LN. Surgical management of anteriorly placed lesions at the craniocervical junction an alternative approach. Acta Neuro chirurgica. 1991;108(1-2):70-77.

26. Batay F, Yakupoğlu H, Ulus A, et al. Foramen magnum tümörlerinde cerrahi strateji. Türk Nöroşirurji Dergisi. 2005;15(1):69-75.

27. Sohn S, Chung CK. Conventional posterior approach without far lateral approach for ventral foramen magnum meningiomas. J Korean Neurosurg Soc. 2013;54(5):373-378.

28. al-Mefty O, Borba LA, Aoki N, et al. The transcondylar approach to extradural nonneoplastic lesions of the craniovertebral junction. $J$ Neurosurg. 1996;84(1):1-6.

29. Salas E, Sekhar LN, Ziyal IM, et al. Variations of the extreme-lateral craniocervical approach:anatomical study and clinical analysis of 69 patients. J Neurosurg. 1999;90(Supp12):206-219.

30. Türe U, Pamir MN. Extreme lateral-transatlas approach for resection of the dens of the axis. J Neurosurg. 2002;96(Suppl1):73-82.

31. Avci E, Dagtekin A, Ozturk AH, et al. Anatomical variations of the foramen magnum, occipital condyle and jugular tubercle. Turk Neurosurg. 2011;21(2):181-190.

32. Liu JK, Rao G, Schmidt $\mathrm{MH}$, et al. Far lateral transcondylar transtubercular approach to lesions of the ventral foramen magnum and craniovertebral junction. Con temp Neurosurg. 2007;29(10):1-8.

33. Murshed KA, Ciçekcibași AE, Tuncer I. Morphometric evaluation of the foramen magnum and variations in its shape: A study on computerized tomographic images of normal adults. Turk J Med Sci. 2003;33(5):301-306.

34. Kizilkanat ED, Boyan N, Soames R, et al. Morphometry of the hypoglossal canal, occipital condyle, and foramen magnum. Neurosurg Q. 2006;16(3):121-125.
35. Barut N, Kale A, Turan Suslu H, et al. Evaluation of the bony landmarks in transcondylar approach. Br J Neurosurg. 2009;23(3):276-281.

36. Tubbs RS, Griessenauer CJ. Morphometric analysis of the foramen magnum :an anatomic study. Neurosurg. 2010;66(2):385-388.

37. Muthukumar N, Swaminathan R, Venkatesh G, et al. A morphometric analysis of the foramen magnum region as it relates to the transcondylar approach. Acta Neurochir (Wien). 2005;147(8):889-895.

38. Scott JHH. The cranial base. Am J Phys Anthropol. 1958;16(3):319-348.

39. Sindel M, Ozkan O, Ucar Y, et al. Foramen magnum' unanatomik varyasyonlari. Akdeni Üniversitesi Tip Fakültesi Dergisi. 1989;6(4):97-102.

40. Açikbaș SC, Tuncer R, Demirez I, et al. The effect of condylectomy on extreme lateral transcondylar approach to the anterior foramen magnum. Acta Neurochir (Wien). 1997;139(6):546-550.

41. Bozbuga M, Oztürk A, Bayraktar B, et al. Surgical anatomy and morphometric analysis of the occipital condyles and foramen magnum. Okajimas Folia Anat Jpn. 1999;75(6):329-334.

42. Olivier G. Biometry of the human occipital bone. J Anat. 1975;120(Pt 3):507-518.

43. Gruber P, Henneberg M, Böni T, et al. Variability of human foramen magnum size. Anat Rec. 2009;292(11):1713-1719.

44. Raikar NA, Meundi MA, David CM, et al. Sexual dimorphism in foramen magnum dimensions in the South Indian population:A digital submentovertex radiographic study. Journal of Forensic Dental Sciences. 2016;8(3):180.

45. Kamath VG, Asif M, Shetty R, et al. Binary logistic regression analysis of foramen magnum dimensions for sex determination. Anat Res Int. 2015;2015:459428.

46. Uthman AT, Al Rawi NH, Al Timimi JF. Evaluation of foramen magnum in gender determination using helical CT scanning. Dentomaxillofac Radiol. 2012;41(3):197-202.

47. Raghavendra Babu YP, Kanchan T, Attiku Y, et al. Sex estimation from foramen magnum dimensions in an Indian population. J Forensic Leg Med. 2012;19(3):162-167.

48. Rai H, Keluskar V, Patil S, et al. Accuracy of measurements of foramen magnum and occipital condyle as an indicator for sex determination using computed tomography. Indian $J$ Health Sci Biomed Res. 2017;10(1):80-83.

49. Bello SS, Zagga AD, Kalale SB, et al. Measurements of occipital condyles using computerised tomography from Sokoto State, Nigeria. Int J Health and Medical Information. 2013;2(3):10-27.

50. Kanodia G, Parihar V, Yadav YR, et al. Morphometric analysis of posterior fossa and foramen magnum. $J$ Neurosci Rural Pract. 2012;3(3):261-266.

51. Sholapurkar Varsha T, Virupaxi RD, Desai SP. Morphometric analysis of human occipital condyles for sex determination in dry adult skulls. Int J Anat Res. 2017;5(1):3318-3323. 